\title{
HEALTH PROMOTING BEHAVIOURS AND LIFESTYLE CHARACTERISTICS OF STUDENTS AT SEVEN UNIVERSITIES IN THE UK
}

\author{
Walid El Ansari ${ }^{1}$, Christiane Stock ${ }^{2}$, Jill John ${ }^{3}$, Pat Deeny ${ }^{4}$, Ceri Phillips ${ }^{3}$, Sherrill Snelgrove ${ }^{3}$, Hamed Adetunjï, \\ Xiaoling $\mathrm{Hu}^{6}$, Sian Parke ${ }^{3}$, Mary Stoate ${ }^{7}$, Andi Mabhala ${ }^{8}$ \\ ${ }^{1}$ Faculty of Sport, Health and Social Care, University of Gloucestershire, Gloucester, United Kingdom \\ 2Unit for Health Promotion Research, Institute of Public Health, University of Southern Denmark, Esbjerg, Denmark \\ ${ }^{3}$ School of Human and Health Sciences, Swansea University, Swansea, Wales, United Kingdom \\ ${ }^{4}$ Institute of Nursing Research, School of Nursing, University of Ulster, Londonderry, Northern Ireland, United Kingdom \\ ${ }^{5}$ School of Health and Social Care, Oxford Brookes University, Oxford, United Kingdom \\ ${ }^{6}$ Faculty of Business, Education and Professional Studies, University of Gloucestershire, Cheltenham, United Kingdom \\ ${ }^{7}$ School of Science, Society and Management, Bath Spa University, Bath, United Kingdom \\ ${ }^{8}$ Faculty of Health and Social Care, University of Chester, Chester, United Kingdom
}

\section{SUMMARY}

Aims: University students' wellbeing and health promoting and damaging behaviours are important and comprise many parameters. The purpose of this study was to assess a range of health behaviours and lifestyle characteristics of 3,706 undergraduate students from seven universities in England, Wales and Northern Ireland. We compared differences in these parameters between males and females, and across the participating universities.

Methods: A self-administered questionnaire assessed socio-demographic information (e.g., gender, age), nutrition, dietary intake and food consumption patterns, as well as the importance of healthy eating, three levels of physical activity, restful sleep, tobacco smoking, use of illicit substance (recreational drugs), frequency of binge drinking and problem drinking. The data was collected in 2007-2008.

Results: While females generally reported lower use of tobacco, illicit substances and alcohol (binge drinking/problem drinking) and consumed more fruits and vegetables, male students had a higher level of physical activity, consumed less sweets and had more restful sleep. When lifestyle characteristics of students were compared between the different universities we observed some 'clustering' of the parameters under study, whereby favourable health practices would be exhibited at some universities; and conversely, the clustering of less favourable practices exhibited at other participating sites.

Conclusions: We conclude that only a minority of students exhibited positive health practices above recommended levels and the level of binge drinking and problem drinking was high. This calls for increased awareness of university administrators, leaders and policy makers to the risky health habits of their students. The observed clustering effects also indicate the need for local (university-specific) health profiles as basis and guidance for relevant health promotion programmes at universities.

Key words: university students, gender, physical activity, healthy nutrition, smoking, illicit drug use, alcohol

Address for correspondence: Walid El Ansari, University of Gloucestershire, Faculty of Applied Sciences, Oxstalls Campus, Oxstalls Lane, Gloucester, Gloucestershire GL2 9HW, United Kingdom. E-mail: walidansari@glos.ac.uk

\section{INTRODUCTION}

University students represent the future decision makers in organizations, communities, and countries. University years are a period where students increasingly make independent choices about their lifestyle and health practices (1). However, the university period also encompasses stresses for students trying to achieve success in their academic goals despite the financial constraints that many report (2). Such stressors, in combination with experiences of 'freedom' from parental restrictions, might support the development of risky lifestyles e.g., high consumption of alcohol and drugs, and a low concern for healthy nutrition and restful sleep. Although some of these practices may be transient in nature, other 'habits' could persevere into middle and old age to cause health hazards later in life. Further, multiplicative detrimental effects can be expected when unhealthy behaviours cluster together. For instance, about $65 \%$ of full-time female students (18-22 years old) at an urban university in the USA exhibited two or more unhealthy behaviours (3), and a cluster analysis on health behaviours among German students indicated that about one quarter of students displayed clustered risks in terms of their behaviours (4). Indeed studies have suggested that students' lifestyles and risk behaviours during the university period raise concern and comprise many issue. 


\section{Health Behaviours}

Nutrition - Food consumption patterns: the nutritional risks specific to college students $(5,6)$ are alarming, to the extent that unhealthy dietary behaviour being one of the six top health risk behaviours of students (7). For instance, in Hong Kong (8) and in Lithuania (9), a low proportion of students consumed fruit and vegetables daily as recommended by the World Health Organization.

Physical Activity: regular physical activity is an important contributor to good health. Increased physical activity has been associated with decreased risk for cardiovascular disease $(10,11)$, type 2 diabetes $(12,13)$, depression (14), and some cancers (15). Nevertheless, in the USA, only $44 \%$ of students reported meeting the international physical activity guidelines in terms of exercising moderately for 30 minutes or vigorously for 20 minutes on 3 of the previous 7 days (16).

Restful Sleep: less research has been undertaken on sleep behaviours of university students e.g. sleep efficiency, sleep onset latency, or actual sleep-time duration (e.g.17). This is despite reports that working students may have their learning ability negatively affected by being tired and sleepy (18). Hence, it has been recommended that educational programs geared to sleep hygiene should be one of the priorities of the curriculum.

Tobacco Smoking: the prevalence of cigarette smoking among some medical students increased during the years of medical education $(19,20)$. A high frequency of smoking among students has been reported $(21,22)$ and this seems to be across many parts of the world. In Jordan, it has been recently reported (23) that 35\% of university students were current smokers. Further, a strong relationship exists between alcohol and tobacco use.

Use of illicit substance (recreational drugs): in Brazil, $15.3 \%$ of university students reported the consumption of several types of illicit drugs, with marijuana being the most used (94\%) (24). In order to relieve the stress and tension of university study, $6.9 \%$ preferred either licit or illicit drug consumption, and 5\% used tranquilizers (24). A high approval of regularly trying and using cocaine, crack, amphetamines and inhalants has been observed among university undergraduate students (25). The higher rates of favourable opinions of students regarding trying and regularly using some psychoactive substances might mirror the global trends in drug use (25).

Alcohol consumption: drinking during the early college years seems a normative behaviour $(26,27)$, and high alcohol use among university students has been an increasingly documented health concern in many countries (28). Such use represents a considerable public health problem (29), and alcohol consumption by university students has received attention (30). A feature is that consuming alcohol among college students seems to arise regardless of students' academic disciplines, with alcohol use evident across all fields of study (31).

\section{AIM OF THE STUDY}

This study is investigated a wide range of reported health behaviours and lifestyle characteristics of students from seven universities in England, Wales and Northern Ireland. The three specific objectives were to:

- Describe the socio-demographic characteristics (e.g. age, gender, marital status and children, living arrangements, and financial sufficiency) and educational features (e.g. year of study, discipline) of the sample;
- Assess the prevalences of a range of health behaviour variables and lifestyle characteristics (e.g. food consumption patterns; physical activity; restful sleep; tobacco smoking; use of illicit substance; and alcohol consumption and problem drinking) of the students by gender; and,

- Compare the participating sites as regards to the health behaviours and lifestyle characteristics of their students.

\section{MATERIAL AND METHODS}

\section{Sample and Data Collection Procedures}

Data used in the present analysis was collected as part of a general Student Health Survey $(2,32,33)$. The UK data was collected in 2007-2008 at the seven participating universities. Cross-sectional epidemiological studies are particularly useful for establishing prevalences and identifying underlying risk factors (34).

Ethical approval was provided by the participating institutions, and self-administered questionnaires were distributed to students during the last 5-10 minutes of their lectures. Participating students did not receive incentives, an information sheet accompanied each questionnaire outlining the research aims and objectives, and all students were informed that participation was voluntary and anonymous. All data were confidential and data protection was observed at all stages of the study. A representative sample of students was sought at all participating universities, and students were informed that by completing the questionnaire, they agree to participate in the study. All data were entered into the computer centrally at one site using the software Teleform ${ }^{\circledR}$; this maximised the quality assurance and minimised any data entry errors.

The current analysis employed data from 3,706 undergraduate students at seven universities in England (University of Gloucestershire, Bath Spa University, Oxford Brookes University, University of Chester, Plymouth University); Wales (Swansea University); and Northern Ireland (University of Ulster). Based on the number of returned questionnaires, the response rate was about $80 \%$.

\section{Health and Wellbeing Questionnaire: Health Behav- iours and Lifestyle Characteristics of Students}

The questionnaire was developed as a general student health and wellbeing survey similar to studies of student lifestyle implemented in several countries $(2,33,35)$. It included sociodemographic information (e.g., gender, age), nutrition, dietary intake and food consumption patterns, as well as the importance of healthy eating, three levels of physical activity, restful sleep, tobacco smoking, use of illicit substance (recreational drugs), frequency of binge drinking and problem drinking.

Assessment of nutrition and importance of healthy eating ( 3 items): participants rated the item "How important is for you to eat healthy?" on a 5-point scale ('very important', 'Not at all important', later recoded into 3 categories.). Students also responded to the question: "How many servings of fruits and vegetables do you usually have per day ( 1 serving $=1$ medium piece of fruit, $1 / 2$ cup chopped, cooked or canned fruits/vegetables, 3/4 cup fruit/vegetable juice, small bowl of salad greens, or $1 / 2$ cup dried fruit)?" The response scales were: 'I don't eat fruits and vegeta- 
bles', '1-2 times', '3-4 times', or '5 or more times'. Participants further completed an item from a food frequency questionnaire that measured their consumption of sweets (chocolate, candy, etc.) (36). "How often do you eat the following foods?" asked participants about the frequency of their usual consumption of sweets (rated on a 5-point scale: 'several times a day', 'daily', 'several times a week', '1-4 times a month', and 'never', later recoded into 4 categories).

Physical Activity (3 items): Respondents rated the items "On how many of the past 7 days did you participate in vigorous exercise for at least 20 minutes?"; "On how many of the past 7 days did you participate in moderate exercise for at least 30 minutes?" (37); and, "On how many of the past 7 days did you do exercises to strengthen or tone muscles (push-ups, sit-ups, or weight lifting)?" (37). The response scales for each of the three items were the number of days, ranging from 1 to 7 days.

Restful Sleep (1 item): students responded to the question: "On how many of the past 7 days did you get enough sleep so that you felt rested when you woke up in the morning?", with the response scales being the number of days (from 1-7 days).

Tobacco Smoking (1 item): participants rated the item "Within the last three months, how often did you smoke? (cigarettes, pipes, cigarillos, cigars)" on a 3-point response scale: 'daily', 'occasionally', and 'never'. Students reporting to be smokers were further asked: "Have you tried to quit smoking within the last 12 months?", scored with dichotomous 'Yes'/ No' response (38).

Use of illicit substance (1 item): students responded to the question "Have you ever use/used drugs?" with three response categories: "Yes, regularly", 'Yes, but only a few times', and 'Never' (adopted from 38).

Frequency of binge drinking (1 item): measured using the question - "Over the last 30 days: How many times (if any) have you had five or more drinks in a row? A "drink" is a glass of wine (ca $15 \mathrm{cl}$ ), a bottle or can of beer (ca $50 \mathrm{cl}$ ), a shot glass of spirits (ca $5 \mathrm{cl}$ ) or a mixed drink, with answer options 'none', '1', '2', '3-5', '6-9', or ' 10 or more' times (adopted from 39).

Problem drinking (1 item): the questionnaire included an alcoholism-screening test, the CAGE test (40). CAGE is a brief screening instrument of four short questions ("Have you ever felt you should cut down on your drinking?"; "Have people annoyed you by criticizing your drinking?"; "Have you ever felt bad or guilty about your drinking?"; "Have you ever had a drink in the morning to get rid of a hangover?"), where each question is scored with dichotomous 'Yes'/'No' response. Two or three affirmative answers suggest problem drinking, while four positive responses indicate serious suspicion of alcohol dependence.

\section{Statistical Analysis}

We calculated frequencies and proportions while computing differences in frequencies between males and females using Chisquare Test. Sex-adjusted prevalences were computed using direct standardization towards a male-to-female ratio of $30 \%$ to $70 \%$ in order to present prevalences of students regarding the different health behaviours by university, whilst taking into account the varying male-to-female ratio of the samples at the different sites.

In order to compare prevalences between study sites we used multivariate logistic regression to calculate Odds Ratios for each site while adjusting for sex. Deviation method was utilised as a contrast method where each university (as predictor variable) was compared to the overall effect. For several variables, some of the response options were combined to satisfy the assumption of adequate cell size for regression analysis. All analyses were performed using the statistical package SPSS 14.0, with significance level set at $\mathrm{p}<0.05$.

\section{RESULTS}

\section{Socio-demographic Characteristics and Educational Features of the Sample}

The total sample $(\mathrm{N}=3,706)$ comprised 970 students from the University of Gloucestershire (43.6\%; mean age 23.3 years \pm 8.4 SD); 485 students from Bath Spa University (22.6\%; mean age 22.2 \pm 6.9 SD); 208 students from Oxford Brookes University (10.8\%; mean age $31.6 \pm 10.4 \mathrm{SD})$; 993 students from the University of Chester (13.1\%; mean age $26 \pm 9.2 \mathrm{SD})$; 169 students

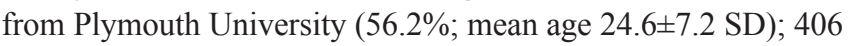
students from Swansea University (7.8\%; mean age $25 \pm 7.4 \mathrm{SD}$ ); and, 474 students from the University of Ulster (8.2\%; mean age 25.2 $\pm 7.7 \mathrm{SD})$. Females comprised the higher proportions of respondents at most of the sites $(77.8 \%)$, probably reflecting the nature of the schools (e.g. Schools of Health Sciences, of Nursing, or of Health and Social Care, etc.) at the participating universities. Females were also more represented in the older age brackets $(\geq 30$ years, mature students). Across the whole sample, $23 \%$ of students reported having children, $56 \%$ were in a relationship or reported having a boyfriend or a girlfriend, and $43 \%$ percent of students regarded their disposable income as sufficient.

Slightly less than half the sample (42.8\%) were attending Year 1 modules, whilst $31.2 \%$ and $3.5 \%$ of students were attending Year 2 and Year 3 respectively. The modules where the students were surveyed contributed to various disciplines including natural sciences $(3.1 \%)$; social sciences $(17.7 \%)$; sport, sport development and exercise modules $(8.1 \%)$ as well as health sciences modules (71.1\%). However, in the UK, multi- and inter-disciplinarily trends are prominent in most higher education institutions' curricula, suggesting that any given module's content is frequently premised on more than one discipline to various extents.

\section{Prevalence of Health and Wellbeing Behaviours and Lifestyle Characteristics by Gender}

Table 1 depicts the behaviours and lifestyle profiles by gender. As regards nutrition, the importance of eating healthy was rated very important/important by slightly more proportions of females, whilst males were more likely to view eating healthy as not at all important/not important. Females were also less likely to eat a few (1-2) fruit/vegetable servings per day, and conversely more likely that they have 3-4 or 5 servings per day. In contrast, less proportions of male students than females consumed sweets (chocolate, candy, etc.) several times a day, daily, or several times per week.

In connection with the levels of physical activity achieved during the week prior to the survey, males were generally more likely to have achieved vigorous or moderate exercise that met the international recommendation guidelines, or to have had undertaken exercises to strengthen or tone their muscles. As for 
Table 1. Health behaviours and lifestyle characteristics by gender

\begin{tabular}{|c|c|c|c|}
\hline \multirow[b]{2}{*}{ Variable } & \multicolumn{2}{|c|}{ Gender } & \multirow[b]{2}{*}{$p$-value ${ }^{d}$} \\
\hline & $\begin{array}{c}\text { Female } \\
(n=1,331)\end{array}$ & $\begin{array}{c}\text { Male } \\
(n=712)\end{array}$ & \\
\hline \multicolumn{4}{|l|}{ Nutrition: importance of eating healthy } \\
\hline Very important/ important & 71.4 & 67.5 & \multirow{3}{*}{$<0.001$} \\
\hline Undecided & 24.4 & 24.8 & \\
\hline Not at all important/not important & 4.2 & 7.8 & \\
\hline \multicolumn{4}{|l|}{ Usual number of fruit/vegetable servings per day ${ }^{a}$} \\
\hline Don't eat fruit/vegetables & 2.1 & 6.5 & \multirow{4}{*}{$<0.001$} \\
\hline $1-2$ servings & 39.3 & 46.2 & \\
\hline $3-4$ servings & 42.2 & 36.0 & \\
\hline$\geq 5$ servings & 16.5 & 11.3 & \\
\hline \multicolumn{4}{|l|}{ How often do you eat sweets (chocolate, candy, etc.) } \\
\hline Several times a day/daily & 28.2 & 24.8 & \multirow{4}{*}{$<0.001$} \\
\hline Several times a week & 42.0 & 37.7 & \\
\hline $1-4$ times a month & 28.2 & 33.6 & \\
\hline Never & 1.6 & 3.9 & \\
\hline \multicolumn{4}{|l|}{ Physical activity: physical activity in previous week } \\
\hline Participate in vigorous exercise $\geq 3$ times for $\geq 20$ minutes & 29.2 & 46.9 & \multirow{3}{*}{$<0.001$} \\
\hline Participate in moderate exercise $\geq 5$ times for $\geq 30$ minutes & 10.8 & 19.0 & \\
\hline Do exercises to strengthen or tone muscles (push-ups, sit-ups, or weight lifting $\geq 2$ times & 19.4 & 38.3 & \\
\hline Sleep: Enough Sleep on $\geq 3$ days in previous week & 63.8 & 68.4 & 0.021 \\
\hline \multicolumn{4}{|l|}{ Smoking: tobacco ${ }^{b}$} \\
\hline Daily & 15.9 & 14.7 & \multirow{3}{*}{0.019} \\
\hline Occasional & 11.0 & 14.6 & \\
\hline Never & 73.1 & 70.7 & \\
\hline Among smokers: \% who tried to quit smoking within last year & 34.8 & 27.5 & 0.006 \\
\hline \multicolumn{4}{|l|}{ Illicit substance: ever use/used illicit substance ${ }^{c}$} \\
\hline Yes, regularly & 3.2 & 9.6 & \multirow{3}{*}{$<0.001$} \\
\hline Yes, but only a few times & 22.3 & 37.2 & \\
\hline Never & 74.6 & 53.2 & \\
\hline \multicolumn{4}{|l|}{ Alcohol } \\
\hline Did not drink any alcohol in the last 3 months preceding the survey & 8.3 & 7.3 & 0.209 \\
\hline Binge drinking (had $\geq$ five drinks in a row in the last two weeks) & 64.6 & 76.4 & $<0.001$ \\
\hline Problem drinking: CAGE score of 2 or more & 21.2 & 31.0 & $<0.001$ \\
\hline
\end{tabular}

All cells are percentages; ${ }^{1} 1$ serving $=1$ medium piece of fruit or $1 / 2$ cup chopped, cooked or canned fruits/vegetables or $3 / 4$ cup fruit/ vegetable juice, or small bowl of salad greens, or $1 / 2$ cup dried fruit; ${ }^{b}$ includes cigarettes, pipe, cigarillos, cigars; ${ }^{~}$ includes ecstasy, marijuana, cocaine, heroin, crack, LSD, amphetamines; ${ }^{\mathrm{d}} \mathrm{p}$-value refers to Chi-square test over all answering categories

the amount of rest required for the body in order to regenerate, there were no gender differences in students getting enough sleep on 3 or more days during the week prior to the survey. Slightly higher proportions of females consumed tobacco daily, and conversely slightly more males reported themselves as occasional smokers. Female smokers were more likely to have attempted to quit smoking within last 12 months prior to the survey. Although $<10 \%$ of men used illicit substance regularly, they were three times more likely than women in their regular use of illicit substance, or about twice more likely to have had used it on a few occasions. In addition, about $10 \%$ more proportions of men than women reported binge drinking and problem drinking.

\section{Self-reported Health Behaviours and Lifestyle Char- acteristics Across Participating Universities}

Results of the sex-standardized rates of physical and psychological health parameters for the whole sample and by university are depicted in Table 2. The comparison shows that some of the 
Table 2. Sex-standardized rates of health behaviours and lifestyle characteristics for the whole sample and by university

\begin{tabular}{|c|c|c|c|c|c|c|c|c|c|}
\hline Variable & $\begin{array}{l}\text { Whole } \\
\text { sample }\end{array}$ & $\begin{array}{c}\text { Site } \\
1\end{array}$ & $\begin{array}{c}\text { Site } \\
2\end{array}$ & $\begin{array}{c}\text { Site } \\
3\end{array}$ & $\begin{array}{c}\text { Site } \\
4\end{array}$ & $\begin{array}{c}\text { Site } \\
5\end{array}$ & $\begin{array}{c}\text { Site } \\
6\end{array}$ & $\begin{array}{c}\text { Site } \\
7\end{array}$ & $p$-value ${ }^{b}$ \\
\hline \multicolumn{10}{|l|}{ Nutrition } \\
\hline $\begin{array}{l}\text { Importance of eating healthy (very important/impor- } \\
\text { tant) }\end{array}$ & 70.2 & $64.2^{* *}$ & $76.0^{*}$ & $66.5^{\star \star *}$ & 68.2 & $84.4^{* * *}$ & 76.7 & 69.9 & $<0.001$ \\
\hline $\begin{array}{l}\text { Usual number of fruit/vegetable servings per day* } \\
\text { ( } \geq 5 \text { servings) }\end{array}$ & 14.9 & 12.0 & 16.3 & $10.6^{* \star *}$ & 18.1 & $28.6^{* * *}$ & $25.6^{\star *}$ & 15.7 & $<0.001$ \\
\hline $\begin{array}{l}\text { How often do you eat sweets (chocolate, candy, etc.) } \\
\text { (<1 time a week/never) }\end{array}$ & 32.1 & 32.5 & 34.2 & $23.6^{\star \star \star}$ & 33.5 & $40.6^{* *}$ & 36.4 & 30.1 & $<0.001$ \\
\hline \multicolumn{10}{|l|}{ Physical activity in previous week } \\
\hline $\begin{array}{l}\text { Participate in vigorous exercise } \geq 3 \text { times for } \geq 20 \\
\text { minutes }\end{array}$ & 34.5 & $24.2^{*}$ & $39.8^{*}$ & $19.7^{\star * \star}$ & 36.3 & $49.5^{\star * \star}$ & $46.4^{* *}$ & $40.6^{*}$ & $<0.001$ \\
\hline $\begin{array}{l}\text { Participate in moderate exercise } \geq 5 \text { times for } \geq 30 \\
\text { minutes }\end{array}$ & 13.3 & 11.9 & 13.0 & $4.1^{* * *}$ & 15.3 & $22.3^{* *}$ & $23.7^{* *}$ & 15.0 & $<0.001$ \\
\hline $\begin{array}{l}\text { Do exercises to strengthen or tone muscles } \\
\text { (push-ups, sit-ups, or weight lifting) } \geq 2 \text { times }\end{array}$ & 25.1 & 20.5 & $31.8^{* * *}$ & $9.5^{* * *}$ & 25.4 & $33.1^{* *}$ & 29.4 & 22.4 & $<0.001$ \\
\hline Enough sleep on $\geq 3$ days in previous week & 49.9 & 41.3 & 51.3 & $34.6^{* * *}$ & $59.6^{*}$ & 54.8 & 56.5 & $62.1^{* * *}$ & $<0.001$ \\
\hline Tobacco** (daily) & 15.5 & 20.8 & $10.5^{* *}$ & $25.8^{* * *}$ & 14.0 & $3.9^{* * *}$ & 17.5 & 13.5 & $<0.001$ \\
\hline Illicit substance use (ever used) & 31.8 & 32.1 & 30.7 & $22.9^{* * *}$ & 30.7 & 33.1 & 34.8 & $41.4^{* * *}$ & $<0.001$ \\
\hline \multicolumn{10}{|l|}{ Alcohol } \\
\hline $\begin{array}{l}\text { Binge drinking (having had } \geq 5 \text { drinks in a row in the } \\
\text { last two weeks) }\end{array}$ & 68.1 & 66.3 & $72.8^{* * *}$ & $70.0^{* *}$ & 64.9 & $58.9^{*}$ & $49.3^{* * *}$ & 67.1 & $<0.001$ \\
\hline Problem drinking: CAGE score of 2 or more & 23.1 & 20.1 & 23.2 & $28.6^{* * *}$ & $17.1^{* * *}$ & 25.5 & 25.3 & 26.2 & $<0.001$ \\
\hline
\end{tabular}

a Male-to-female ratio of $30: 70$, all universities are anonymous for confidentiality; all cells are column percentages

${ }^{b} \mathrm{p}$-values for an effect across the participating universities based on logistic regression models adjusted for sex; values in bold indicate statistical significance where significance levels indicate differences between each university and the whole sample, i.e. each university is compared to the overall sample's mean, where * $<<0.05$, ${ }^{* *} p<0.01$, and ${ }^{* * *} p<0.001$

participating sites exhibited more favourable prevalences across many of the health practices under study. For instance, students at site 5 generally reported a clustering of favourable levels of the variables under study: more healthy nutrition and physical activity combined together with a lower rate of smoking and binge drinking than the sample's average. Similar to this advantageous pattern of clustering but to a lesser extent, students from site 6 also showed better levels than the sample's average in some practices (fruit/vegetable consumption, moderate and vigorous physical activity and binge drinking).

Conversely, compared to the sample's averages, participants from site 3 exhibited a less favourable 'overall situation' across the health practices: a lower level of healthy nutrition and physical activity combined, less restful sleep together with more tobacco, illicit drug and alcohol consumption (binge drinking, problem drinking) than the sample's average. The other universities did not display such a clear pattern in any of the two directions, fairing well on some parameters and conversely doing less well on other parameters when compared with the means of the whole sample.

\section{DISCUSSION}

This study investigated a range of self-reported health behaviours and lifestyle features of students from seven universities in England, Wales and Northern Ireland. The size and importance of this population that comprise the highly educated segments of young adults is receiving increased attention (e.g. 2, 33, 41-43) by educators, decision makers and public health policies. The present study increases our knowledge of the health profiles of these young adults, and adds to our understanding of the health promoting variables that contribute to the wellbeing of university students, or alternatively any of the damaging lifestyle characteristics that could compromise their present and future health.

In connection with nutrition, our sample showed that $16.5 \%$ female and $11.3 \%$ males ate 5 or more fruit/vegetable servings daily. This is higher than in the USA, where $7.9 \%$ of college and university students reported that they consumed 5 or more fruit/ vegetable servings daily (44). However, despite the guidelines and dietary recommendations (45), about $86 \%$ of our sample ate $<5$ servings of fruits and vegetables of fruit/ vegetable servings per day. Nevertheless, this still compared favourably with Germany where about $95 \%$ first year university students ate $<5$ servings of fruits and vegetables (46). In contrast, in Hong Kong, 36\% and $34 \%$ of female and male university students respectively ate two to four servings of fruit each day, and $55 \%$ and $41 \%$ ate three to five servings of vegetables each day (8). However, in connection with the consumption of sweets (chocolate, candy, etc.), $\approx 28 \%$ female and $34 \%$ males in our sample reported that they consumed such items 1-4 times a month, which could be comparable to the proportions of students in Hong Kong who indicated that they limit use of sugars and food containing sugar (23\% female and $29 \%$ males) (8). Making the choices to increase fruit and vegetable consumption is a simple and inexpensive prevention 
strategy that 18- to 24-year-olds can use to reduce their risk of chronic disease (47).

In relation to physical activity, the findings of the present study indicated that $40 \%$ of females and $66 \%$ of males participated either in vigorous exercise for at least 20 minutes on $\geq 3$ days in the week preceding the survey, or participated in moderate exercise for at least 30 minutes on $\geq 5$ days in the week preceding the survey. This is analogous to reports from the USA, where $44.2 \%$ of students exercised vigorously for at least 20 minutes or moderately for at least 30 minutes on at least 3 out of the past 7 days (44). Similarly the exercise levels of the UK sample described in this paper appear encouraging (29\% females and $47 \%$ males) when compared to Hong Kong, where 9\% female and 26\% male university students exercised vigorously for $20 \mathrm{~min}$ or more at least three times a week(8).

Pertaining to strengthening exercises, in this UK sample, 19\% female and 38\% male students undertook exercises to strengthen or tone muscles (e.g. push-ups, sit-ups, or weight lifting) at least 2 times during the week preceding the survey, as compared to the USA counterparts where about $48 \%$ reported that they exercised to strengthen or to tone muscles on at least 2 out of the past 7 days (44). However, the levels reported by our UK sample appear hopeful in relation to Hong Kong, where $18 \%$ female and $28 \%$ male students reported doing stretching exercises at least three times per week (8).

With reference to restful sleep, our findings indicated that $64 \%$ female and $68 \%$ male students reported that they had enough sleep on $\geq 3$ days in the week preceding the survey. In the USA survey by the College Health Association, $71 \%$ of students reported getting enough sleep to wake feeling rested on at least 5 of the past 7 days (44). In Hong Kong, about $25.7 \%$ of the females and $26.2 \%$ of the males out of 247 students recruited at various locations on campus reported that they get enough sleep (1). This might not be surprising; students are less likely to get adequate sleep because they are pursuing their university education (8).

As for consumption of tobacco products, in our UK sample $73 \%$ female and $71 \%$ male students had never smoked, which is slightly higher than in the USA where $65 \%$ of the surveyed students reported that they never used cigarettes (44). However such levels of UK student non-smokers parallel the levels described in Spanish (67.6\%), German (75.5\%) and Lithuanian (76\%) students who indicated that they never smoked or did so on few particular occasions (41).Conversely, more than a quarter $(27 \%$ females and $29 \%$ males) our sample smoked either daily or occasionally. Perhaps such levels could be due to cigarette use that was initiated among younger adolescents in the early 1990s. These cohorts carried their higher levels of smoking with them through the high school years and ultimately into college (48).

As for the use illicit substance/s, we found that $75 \%$ female and $53 \%$ male students never used illicit substance, comparable to levels in the USA where $65.5 \%$ of the students reported they never used marijuana (44). In contrast, our rates of regular or little (few times) use of illicit substance/s were in $25 \%$ of females and $47 \%$ of males. Given the methodological differences of the measurement of 'drug' use that was employed in published studies, as well as the type of elicit substance that different studies examined in college student populations, comparison of our results with other studies is not a straight forward task. For instance, employing USA estimates, about one in three college students in 1980-81 was a current marijuana user, which then dropped by more than a half
$(<15 \%)$ in the first 4 years of the 1990 s, followed by an increase in the mid-1990s, with the rate exceeding 20\% in 1999 (49).

As regards the consumption of alcohol, we found that $8 \%$ of females and $7 \%$ of the males reported that they did not drink any alcohol in the last 3 months preceding the survey. This compared low with the USA where $17 \%$ of the students reported never using alcohol (44). However, other reviews that were based on five different sources of data in order to estimate recent levels of alcohol (and other drug) use among college students in the USA, reported that almost one third had not had even a single drink in the prior 30 days (49). Conversely in our sample about $65 \%$ female and $76 \%$ male students had binged $\geq 5$ drinks in a row in the last two weeks. Research (49) showed that $40 \%$ of college students in the 1999 MTF Monitoring the Future study (48) reported having engaged in heavy drinking at least once in the past 2 weeks. Several studies in the USA have found that "approximately 2 of 5 American college students can be termed binge drinkers" (50, p. 122). The recorded levels of binge drinking among female and male students are extremely varied between studies (51), the variables associated with binge drinking are many, and interestingly, binge drinking could be associated with risky health behaviour (tobacco consumption), and conversely also with positive health behaviours (e.g. greater physical activity) (52). Whilst problem drinking in our sample was about $21 \%$ females and $31 \%$ males, others have reported that $15-25 \%$ of college students who drink engage in heavy or problematic drinking $(53,54)$. As with the case of illicit drug use (see above), the comparisons between findings of different studies are complicated due to inconsistencies in the terms employed to describe drinking behaviour (51). Nevertheless, drinking alcohol in the period of college and university study is an important social challenge that deserves research attention, and the consequences and implications of binge and hazardous drinking among young people including university students comprise a challenge of shared international concern (55-57).

An interesting point to note is that the findings of this study indicated a degree of clustering of a 'more favourable' or 'less favourable' levels of the variables across particular participating sites. For instance, site 3 exhibited values that were significantly less than the whole sample's average as regards the favourable variables, and significantly more than the sample's average as regards the less favourable variables (with the exception of illicit substance use). Conversely, site 5 displayed the opposite pattern of clustering: values that were higher than the whole sample's average for the favourable variables, and less than the sample's average in the less favourable variables. Generally the remaining sites had mixed levels of favourable variables and of less favourable variables. The possible assumptions for such clustering patterns are not straight forward to hypothesize. Such collection (gathering) of 'favourable' or 'less/un favourable' health behaviours and practices could reflect a variety of unique aspects that might characterize the university, its 'environment', its policies, and/or procedures for the selection of students and the ensuing composition of the student population. We have reported such collections (gathering) of 'favourable' or 'less/un favourable' health factors and practices elsewhere (58), and have further suggested the relationships of such findings with macro-level aspects such as income, gender issues, political models, and social rights which could act as mediatory factors that might moderate attitudes (33). In agreement, others $(3,4)$ have reported similar clustering where, 
at the individual person level, habits and practices or (healthy and unhealthy) behaviours could cluster in certain individuals.

This study has limitations. It is a (descriptive) prevalence study and thus generalizations of the findings should be cautious. Subjective self reported data could introduce inaccuracies due to recall bias, social desirability and sociability. Students were recruited during lessons/lectures, hence those not present in the class at the time of data collection were not included in the survey. Some variables were assessed by single item measures due to respondent burden and the need that a general student health survey be conducted within a short time during the lectures. This renders the measurement of each health variable with more items unworkable. There are many other instruments that measure health behaviours, but most cover only a single aspect of health-promoting lifestyles (59-62). In addition, females were over-represented in this UK sample, hence, our data is presented categorised by gender and standardised for gender when undertaking comparisons across the participating sites. Although we standardized for gender, our male-to-female ratio might not be completely comparable to that of the UK as a whole. We broadened the data collection at the participating sites in order get student samples that are representative of their universities; however, our sample remains a convenience sample. Such convenience samples are common in student surveys across the world $(1,44,47,63)$. Even when response rates are relatively high, possibly due to data collection being undertaken in the class/ lecture room, students not interested in healthful practices could be under-represented in our samples leading to an underestimation of unfavourable such practices. The data that was collected did not include variables related to the background of the University as well as the background of the students and the situational context. Such information would have enabled a detailed comparison of potential explanations of the differences found between the participating universities. Likewise, the degree of observed clustering of a more or less favourable levels of the variables at some universities might be subject to many factors (usually not measured) that would confound such complex and intricately associated constellations of relationships that are usually challenging to unpack, let alone attribute to certain aspects of the university, region, country or participating individuals (58). Future research should attempt to address these limitations.

\section{CONCLUSION}

Overall this research concludes that only a minority of students exhibited positive health practices at international recommended levels as regards fruit/vegetable consumption and physical activity. Conversely, large proportions of the sample engaged in risk taking behaviours such as binge drinking and illicit drug use. Even when the prevalence of some advantageous behaviours of the UK students were slightly more positive than those of students from other countries, this calls for increased awareness of university leaders and decision makers to the health and well-being needs of students. We found remarkable clustering effects of advantageous as well as disadvantageous health practices among students from certain sites which highlighted the need for university-specific local health profiles as a well-founded basis for health promotion programmes implemented at universities. Universities should support healthy lifestyles of students through healthy food choices, a range of campus sports and exercise activities, in addition to appropriate health-enhancing alcohol and smoking policies. Moreover, while generic health promotion programmes could be useful in many settings, as seen in this study, such unique 'individuality' of each participating site requires attention. In such instances, generic programmes would need to be revisited and individually refined/tailored to the needs of a given university at a point in time. This also confirmed the need for continual longitudinal monitoring processes of student health and wellbeing at universities to act as a 'barometer' of the constantly changing health needs of different student cohorts. Many of these processes are still not in place.

\section{Acknowledgements}

The authors wish to acknowledge the students and universities who participated in this study. In addition we wish to acknowledge the UK Student Health Group (J. John, P. Deeny, C. Phillips, S. Snelgrove, H. Adetunji, X. Hu, S. Parke, M. Stoate, A. Mabhala). We also thank the anonymous reviewers for their constructive comments that helped strengthen the article.

\section{REFERENCES}

1. Lee DH, Kang S, Zum S. A qualitative assessment of personal and academic stressors among Korean Collage students: an exploratory study. College Student Journal. 2005;39(3):442.

2. El Ansari W, Stock C. Is the health and wellbeing of university students associated with their academic performance? Cross sectional findings from the United Kingdom. Int J Environ Res Public Health. 2010 Feb;7(2):509-27.

3. Quintiliani L, Allen J, Marino M, Kelly-Weeder S, Li Y. Multiple health behavior clusters among female college students. Patient Educ Couns. 2010 Apr;79(1):134-7.

4. Allgöwer A. Health promotion at the university: The health status of students. Opladen: Leske and Budrich; 2000.

5. Gores SE. Addressing nutritional issues in the college-aged client: strategies for the nurse practitioner. J Am Acad Nurse Pract. 2008 Jan;20(1):510.

6. Krinke U. Adult nutrition. In: Brown J, editor. Nutrition through the life cycle. Belmont: Wadsworth/Thomson Learning; 2002. p. 383-407.

7. Lowry R, Galuska DA, Fulton JE, Wechsler H, Kann L, Collins JL. Physical activity, food choice, and weight management goals and practices among US college students. Am J Prev Med. 2000 Jan;18(1):18-27.

8. Lee RL, Loke AJ. Health-promoting behaviors and psychosocial wellbeing of university students in Hong Kong. Public Health Nurs. 2005 May-Jun;22(3):209-20.

9. Skemiene L, Ustinaviciene R, Piesine L, Radisauskas R. Peculiarities of medical students' nutrition. Medicina (Kaunas). 2007;43(2):145-52.

10. Manson JE, Greenland P, LaCroix AZ, Stefanick ML, Mouton CP, Oberman A, et al. Walking compared with vigorous exercise for the prevention of cardiovascular events in women. N Engl J Med. $2002 \mathrm{Sep}$ 5;347(10):716-25.

11. Richardson CR, Kriska AM, Lantz PM, Hayward RA. Physical activity and mortality across cardiovascular disease risk groups. Med Sci Sports Exerc. 2004 Nov;36(11):1923-9.

12. Knowler WC, Barrett-Connor E, Fowler SE, Hamman RF, Lachin JM, Walker EA, et al.; Diabetes Prevention Program Research Group. Reduction in the incidence of type 2 diabetes with lifestyle intervention or metformin. N Engl J Med. 2002 Feb 7;346(6):393-403.

13. Tuomilehto J, Lindström J, Eriksson JG, Valle TT, Hämäläinen H, IlanneParikka P, et al.; Finnish Diabetes Prevention Study Group. Prevention of type 2 diabetes mellitus by changes in lifestyle among subjects with impaired glucose tolerance. N Engl J Med. 2001 May 3;344(18):1343-50.

14. Blumenthal JA, Babyak MA, Moore KA, Craighead WE, Herman S, Khatri $\mathrm{P}$, et al. Effects of exercise training on older patients with major depression. Arch Intern Med. 1999 Oct 25;159(19):2349-56.

15. Wolin KY, Yan Y, Colditz GA, Lee IM. Physical activity and colon cancer prevention: a meta-analysis. Br J Cancer. 2009 Feb 24;100(4):611-6. 
16. American College Health Association. American College Health Association National College Health Assessment (ACHA-NCHA) Spring 2005 Reference Group Data Report (Abridged). J Am Coll Health. 2006 Jul-Aug;55(1):5-16.

17. Lehnkering H, Siegmund R. Influence of chronotype, season, and sex of subject on sleep behavior of young adults. Chronobiol Int. 2007;24(5):875-88.

18. Teixeira LR, Fischer FM, Lowden A. Sleep deprivation of working adolescents - a hidden work hazard. Scand J Work Environ Health. 2006 Aug;32(4):328-30.

19. Richmond R. Teaching medical students about tobacco. Thorax. 1999 Jan;54(1):70-8

20. Davis R. When doctors smoke. Tob Contr. 1993;2(3):187-8.

21. Young EH. Relationship of residents' emotional problems, coping behaviors, and gender. J Med Educ. 1987 Aug;62(8):642-50.

22. Stewart SM, Betson C, Marshall I, Wong CM, Lee PW, Lam TH. Stress and vulnerability in medical students. Med Educ. 1995 Mar;29(2):119-27.

23. Khader YS, Alsadi AA. Smoking habits among university students in Jordan: prevalence and associated factors. East Mediterr Health J. 2008 Jul-Aug;14(4):897-904

24. Carvalho KA, Sant'Anna MJ, Coates V, Omar HA. Medical students: abuse of psychoactive substances and sexuality aspects. Int J Adolesc Med Health. 2008 Jul-Sep;20(3):321-8.

25. Stempliuk Vde A, Barroso LP, Andrade AG, Nicastri S, Malbergier A. Comparative study of drug use among undergraduate students at the University of São Paulo - São Paulo campus in 1996 and 2001. Rev Bras Psiquiatr. 2005 Sep;27(3):185-93.

26. Dusenbury L, Botvin GJ. Applying the competency enhancement model to substance abuse prevention. In: Albee GW, Kessler M, Goldston SE Joff JM, editors. The present and future of prevention: in honor of George W. Albee. Newbury Park: Sage Publications; 1992. p. 182-95.

27. Hillman SB, Sawilowsky SS. A comparison of two grouping methods in distinguishing levels of substance use. J Clin Child Psychol. 1992;21(4):348-53.

28. Karam E, Kypri K, Salamoun M. Alcohol use among college students: an international perspective. Curr Opin Psychiatry. 2007 May;20(3):213-21.

29. Martens MP, Dams-O'Connor K, Beck NC. A systematic review of college student-athlete drinking: prevalence rates, sport-related factors, and interventions. J Subst Abuse Treat. 2006 Oct;31(3):305-16.

30. Stock C, Mikolajczyk R, Bloomfield K, Maxwell AE, Ozcebe H, Petkeviciene J, et al. Alcohol consumption and attitudes towards banning alcohol sales on campus among European university students. Public Health. 2009 Feb;123(2):122-9.

31. Barber MW, Fairclough A. A comparison of alcohol and drug use among dental undergraduates and a group of non-medical, professional undergraduates. Br Dent J. 2006 Nov 11;201(9):581-4; discussion 576.

32. El Ansari W, Maxwell AE, Mikolajczyk RT, Stock C, Naydenova V, Krämer A. Promoting public health: benefits and challenges of a Europeanwide research consortium on student health. Cent Eur J Public Health. 2007 Jun;15(2):58-65.

33. El Ansari W, Clausen SV, Mabhala A, Stock C. How do I look? Body image perceptions among university students from England and Denmark. Int J Environ Res Public Health. 2010 Feb;7(2):583-95.

34. Kelsey J, Whittemore AS, Evans AS, Thompson WD. Methods in observational epidemiology. New York: Oxford University Press; 1996.

35. El Ansari W, Maxwell AE, Stock C, Mikolajczyk R, Naydenova V, Krämer A. Nurses' involvement in international research collaborations. Nurs Stand. 2007 Mar 7-13;21(26):35-40.

36. Mikolajczyk RT, El Ansari W, Maxwell AE. Food consumption frequency and perceived stress and depressive symptoms among students in three European countries. Nutr J. 2009 Jul 15;8:31

37. Haskell WL, Lee IM, Pate RR, Powell KE, Blair SN, Franklin BA, et al.; American College of Sports Medicine; American Heart Association. Physical activity and public health: updated recommendation for adults from the American College of Sports Medicine and the American Heart Association. Circulation. 2007 Aug 28;116(9):1081-93.

38. Hurrelmann K, Kolip P. The Youth Health Survey. Public Relations Service, SFB 227, No 11. Bielefeld: University of Bielefeld; 1994

39. Winther Ringgard L, Birk Nissen S, Nielsen GA. Lifestyle and everyday life of the youth 2003. Copenhagen, Denmark: Danish Cancer Society and National Board of Health; 2005.

40. Ewing JA. Detecting alcoholism. The CAGE questionnaire. JAMA. 1984 Oct 12;252(14):1905-7.

41. Stock C, Kücük N, Miseviciene I, Guillén-Grima F, Petkeviciene J, Aguinaga-Ontoso I, et al. Differences in health complaints among uni- versity students from three European countries. Prev Med. 2003 Dec;37(6 Pt 1):535-43.

42. Mikolajczyk RT, Brzoska P, Maier C, Ottova V, Meier S, Dudziak U, et al. Factors associated with self-rated health status in university students: a cross-sectional study in three European countries. BMC Public Health. 2008 Jun 18;8:215.

43. Mikolajczyk RT, Maxwell AE, El Ansari W, Naydenova V, Stock C, Ilieva S, et al. Prevalence of depressive symptoms in university students from Germany, Denmark, Poland and Bulgaria. Soc Psychiatry Psychiatr Epidemiol. 2008 Feb;43(2):105-12.

44. American College Health Association. American College Health Association National College Health Assessment Spring 2006 Reference Group data report (abridged). J Am Coll Health. 2007 Jan-Feb;55(4):195-206.

45. US Department of Health and Human Services. Healthy people 2010: understanding and improving health. Washington, DC: US Government Printing Office; 2000.

46. Keller S, Maddock JE, Hannöver W, Thyrian JR, Basler HD. Multiple health risk behaviors in German first year university students. Prev Med. 2008 Mar;46(3):189-95.

47. Richards A, Kattelmann KK, Ren C. Motivating 18- to 24-year-olds to increase their fruit and vegetable consumption. J Am Diet Assoc. 2006 Sep;106(9):1405-11.

48. National Institute on Drug Abuse. National survey results on drug use from monitoring the future study. Rockville: National Institute on Drug Abuse; 2000

49. O’Malley PM, Johnston LD. Epidemiology of alcohol and other drug use among American college students. J Stud Alcohol Suppl. 2002 Mar;(14):23-39.

50. Wechsler H, Austin SB. Binge drinking: the five/four measure. J Stud Alcohol. 1998 Jan;59(1):122-4.

51. Gill JS. Reported levels of alcohol consumption and binge drinking within the UK undergraduate student population over the last 25 years. Alcohol Alcohol. 2002 Mar-Apr;37(2):109-20.

52. Vickers KS, Patten CA, Bronars C, Lane K, Stevens SR, Croghan IT, et al. Binge drinking in female college students: the association of physical activity, weight concern, and depressive symptoms. J Am Coll Health. 2004 Nov-Dec;53(3):133-40.

53. Barnes GM, Welte JW, Dintcheff B. Alcohol misuse among college students and other young adults: findings from a general population study in New York State. Int J Addict. 1992;27(8):917-34.

54. Berkowitz AD, Perkins HW. Problem drinking among college students: a review of recent research. J Am Coll Health. 1986 Jul;35(1):21-8.

55. Wechsler H, Kuo M. College students define binge drinking and estimate its prevalence: results of a national survey. J Am Coll Health. 2000 Sep;49(2):57-64.

56. Hingson R, Heeren T, Winter M, Wechsler H. Magnitude of alcohol-related mortality and morbidity among U.S. college students ages 18-24: changes from 1998 to 2001. Annu Rev Public Health. 2005;26:259-79.

57. Saunders JB, Kypri K, Walters ST, Laforge RG, Larimer ME. Approaches to brief intervention for hazardous drinking in young people. Alcohol Clin Exp Res. 2004 Feb;28(2):322-9.

58. El Ansari W, Stock C; UK Student Health Group, Snelgrove S, Hu X, Parke S, et al. Feeling healthy? A survey of physical and psychological wellbeing of students from seven universities in the UK. Int J Environ Res Public Health. 2011 May;8(5):1308-23.

59. Felton GM. Female adolescent contraceptive use or nonuse at first and most recent coitus. Public Health Nurs. 1996 Jun;13(3):223-30.

60. Felton GM, Parsons MA. Factors influencing physical activity in average-weight and overweight young women. J Community Health Nurs. 1994;11(2):109-19.

61. Gillis AJ. Determinants of health-promoting lifestyles in adolescent females. Can J Nurs Res. 1994;26(2):13-28.

62. Walker SN, Sechrist KR, Pender NJ. The health-promoting lifestyle profile: development and psychometric characteristics. Nurs Res. 1987 Mar-Apr;36(2):76-81.

63. Pei-Lin H. Factors influencing students' decisions to choose healthy or unhealthy snacks at the University of Newcastle, Australia. J Nurs Res. 2004 Jun;12(2):83-91 